\title{
Extralobar pulmonary sequestration infected with Mycobacterium gordonae
}

\author{
Yukio Umeda, $\mathrm{MD}, \mathrm{PhD},{ }^{\mathrm{a}}$ Yukihiro Matsuno, $\mathrm{MD}, \mathrm{PhD},{ }^{\mathrm{a}}$ Matsuhisa Imaizumi, $\mathrm{MD}, \mathrm{PhD},{ }^{\mathrm{a}}$ Yoshio Mori, $\mathrm{MD}, \mathrm{PhD},{ }^{\mathrm{a}}$ \\ Hitoshi Iwata, MD, PhD, ${ }^{\mathrm{b}}$ and Hiroshi Takiya, $\mathrm{MD}, \mathrm{PhD},{ }^{\mathrm{a}}$ Gifu, Japan
}

Pulmonary sequestration is a malformation composed of dysplastic lung tissue without normal communication with the tracheobronchial tree and with an anomalous systemic arterial supply. ${ }^{1}$ Few cases of pulmonary sequestration infected with tuberculous or nontuberculous mycobacterium have been reported. ${ }^{2-4}$ However, all of those reports were of intralobar pulmonary sequestrations. In the present article, we describe the first case of extralobar sequestration infected with Mycobacterium gordonae.

\section{CLINICAL SUMMARY}

In August of 2005, a 72-year-old woman was referred to the Gifu Prefectural General Medical Center for abnormal shadow on chest $\mathrm{x}$-ray. Contrast media-enhanced computed tomography (CT) revealed an aberrant arterial supply arising from the left gastric artery to the left basal area (Figure 1, $A$ and $D$ ). Venous drainage from the basal area was through the left lower pulmonary vein (Figure 1, $D$ ). Pulmonary sequestration was diagnosed, and surgical intervention was recommended. However, she rejected surgical intervention. In November of 2007, she was referred to the Gifu Prefectural General Medical Center again for a persistent fever and consolidation on chest $\mathrm{x}$-ray and CT (Figure 1, B). Pneumonia associated with pulmonary sequestration was diagnosed, and she was treated with antibiotics (clarithromycin). At that time, she accepted the recommendation for surgical intervention. On her admission in January of 2008, pneumonia on chest CT was improved but consolidation in the basal area was residual (Figure 1,C).

We scheduled a left lower lobectomy because the venous drainage through the pulmonary vein suggested an intralobar sequestration. Via a lateral thoracotomy, the sequestrated lung was surrounded by independent pleura. Neither obvious adhesion nor connection with the normal

\footnotetext{
From the Departments of Cardiovascular Surgery ${ }^{\mathrm{a}}$ and Pathology, ${ }^{\mathrm{b}}$ Gifu Prefectural General Medical Center, Gifu, Japan.

Received for publication Feb 25, 2008; accepted for publication March 2, 2008.

Address for reprints: Yukio Umeda, MD, PhD, Department of Cardiovascular Surgery, Gifu Prefectural General Medical Center, 4-6-1 Noishiki, Gifu city, 500-8717, Gifu,

Japan (E-mail: yukioumeda@mvd.biglobe.ne.jp).

J Thorac Cardiovasc Surg 2009;137:e23-4

$0022-5223 / \$ 36.00$

Copyright (C) 2009 by The American Association for Thoracic Surgery

doi:10.1016/j.jtcvs.2008.03.040
}

lung was found except around the left lower pulmonary vein. We diagnosed it as extralobar sequestration and planned a simple excision of the sequestrated lung. We divided the aberrant artery and drainage vein and excised the sequestrated lung using a linear stapler. The postoperative course was uneventful.

Histopathologic study revealed destruction of alveolar and reconstruction of respiratory epithelium within its own pleura. The alveolar spaces were filled by mucoid or mononuclear cells. Caseating epithelioid granulomas and Langhans' giant cells were also observed (Figure 2). The diagnosis was of an extralobar pulmonary sequestration infected with Mycobacterium. M. gordonae was identified from the culture of preoperatively collected sputum and surgical specimen by the DNA-DNA hybridization method. Postoperative antimycobacterial chemotherapy was not performed because of the patient's rejection and lack of any clinical symptoms.

\section{DISCUSSION}

Pulmonary sequestration is a malformation composed of dysplastic lung tissue without normal communication with the tracheobronchial tree and with an anomalous systemic arterial supply. ${ }^{1}$ A sequestration without any separation in the pulmonary lobe is classified as intralobar sequestration, whereas a sequestration with independent pleura is classified as extralobar sequestration. Almost always, venous drainage is to the pulmonary veins in intralobar sequestration and to a systemic vein in extralobar sequestration. In extralobar sequestration, venous drainage into the pulmonary vein, as found in our case, is rare. ${ }^{5}$ Although respiratory distress, intrapleural hemorrhage, or congestive heart failure caused by left-to-right shunt may represent the revealing symptoms, repeated bacterial infections are the most frequent modality of presentation of the disease. In our case, M. gordonae was responsible for the infection. Few cases of intralobar pulmonary sequestration infected with tuberculous or nontuberculous Mycobacterium have been reported. ${ }^{2-4}$ In those intralobar sequestration cases, Mycobacterium might have reached the sequestration through Kohn's pore or the bloodstream. A hematogenous route was less possible in our case because any other evident site of pulmonary or extrapulmonary Mycobacterial infection was absent. On the other hand, infection through the Kohn's pore was possible for 2 reasons. 1) Our case had a partial continuity with the normal 

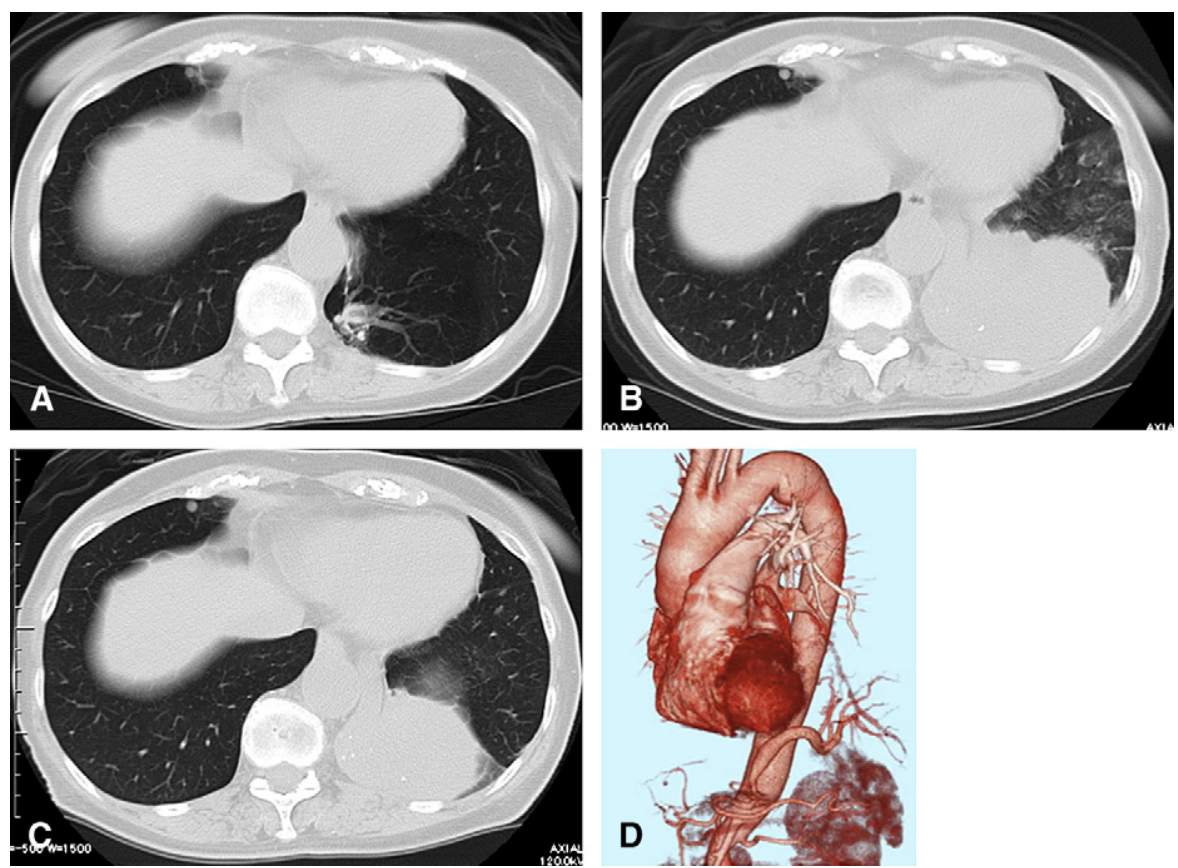

FIGURE 1. CT scans in August of 2005 (A), November of 2007 (B), and January of 2008 (C). Contrast media-enhanced 3-dimensional CT scan (D).

lung just around the left lower pulmonary vein, which was the drainage vein. 2) Extension of pneumonia to the normal lung was revealed by CT scan in November of 2007.

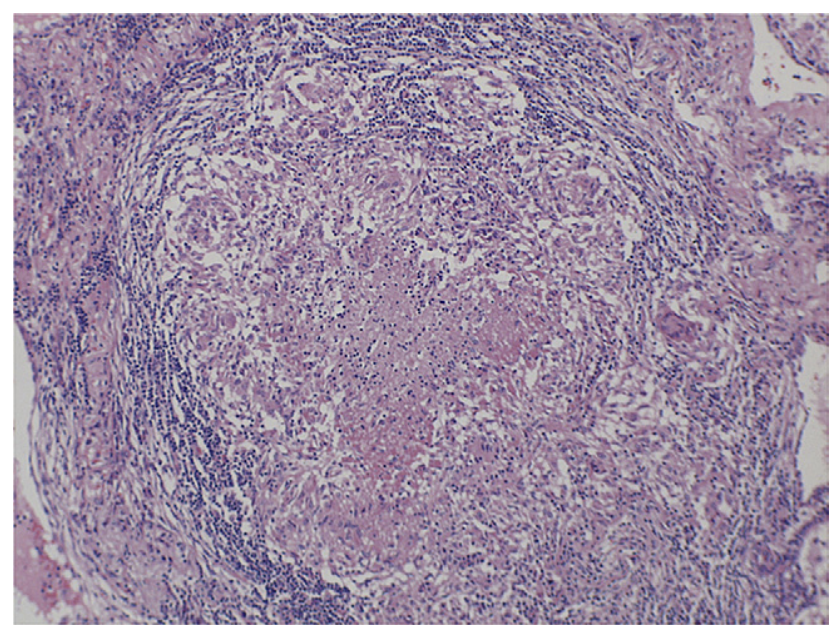

FIGURE 2. Histopathologic appearance of the sequestrated lung.

\section{CONCLUSIONS}

Infection with Mycobacterium may complicate a case even in extralobar pulmonary sequestration in the absence of any other apparent site of Mycobacterium infection. Surgical intervention allows the establishment of the exact diagnosis (eg, intralobar or extralobar) and the immediate removal of the infectious focus.

\section{References}

1. Pryce DM. Lower accessory pulmonary with intralobar sequestration of lung: report of seven cases. J Pathol Bacteriol. 1946;58:457-67.

2. Yatera K, Izumi M, Imai M, Ikegami T, Miyazaki N, Kido M. Intralobar sequestration with tuberculous infection confined to the sequestrated lung. Respirology. 2005; $10: 685-8$.

3. Miyazaki H, Gemma H, Koshimizu N, Sato M, Uemura K, Tamura R, et al. Two cases of intralobar pulmonary sequestration associated with nontuberculous mycobacterial infection in a young patient. Nihon Kokyuki Gakkai Zasshi. 2004;42: 277-83.

4. Shiota Y, Arikita H, Aoyama K, Horita N, Hiyama J, Ono T, et al. Pulmonary sequestration associated by Mycobacterium intracellulare infection. Intern Med. 2002;41:990-2.

5. Gezer S, Taştepe I, Sirmali M, Findik G, Türüt H, Kaya S, et al. Pulmonary sequestration: a single-institutional series composed of 27 cases. $J$ Thorac Cardiovasc Surg. 2007; 133:955-9. 